\title{
NEW ANTIMICROBIAL COMBINATIONS: SUBSTITUTED CHALCONES- OXACILLIN AGAINST METHICILLIN RESISTANT STAPHYLOCOCCUS AUREUS
}

\author{
Juan Manuel Talia*, Nora Beatriz Debattista, Nora Beatriz Pappano
}

Laboratory of Physical Chemistry, Department of Chemistry, San Luis National University, Lavalle 1155. 5700 San Luis, Argentina.

Submitted: April 30, 2010; Returned to authors for corrections: June 28; Approved: January 13, 2011.

\begin{abstract}
Staphylococcus aureus, the most virulent Staphylococcus species, is also the prevalent pathogen isolated from hospitalized patients and the second most common from patients in outpatient settings. In general, bacteria have the genetic ability to transmit and acquire resistance to drugs, which are utilized as therapeutic agents. Related studies of antimicrobial activity indicate that crude extracts containing flavonoids, triterpenes and steroids have showed significative activity against several Staphylococcus aureus strains. Combination effects between flavonoids and antibiotics also have been reported. The aim of the present work was to investigate in vitro synergism between several chalcones substituted in combination with oxacillin, an antibiotic used conventionally against S. aureus ATCC 43300 that is resistant to meticillin, using the kinetic turbidimetric method developed earlier. The results were satisfactory for all assayed combinations and in accordance with the mechanism of bacteriostatic inhibition previously proposed, except for 2',4'-dihydroxy-3'-methoxychalcone - oxacillin. The best combination was $2^{\prime}, 3^{\prime}$-dihydroxychalcone oxacillin (MIC: $11.2 \mu \mathrm{g} / \mathrm{mL}$ ). Further investigations are needed to characterize the interaction mechanism with antibiotics. Thus, chalcones - oxacillin combination could lead to the development of new antibiotics against methicillin resistant $S$. aureus infection.
\end{abstract}

Key words: substituted chalcones, oxacillin, combinations, antimicrobial, S. aureus

\section{INTRODUCTION}

Staphylococcus aureus, the most virulent Staphylococcus species, is also the prevalent pathogen isolated from hospitalized patients and the second most common from patients in outpatient settings (14). Humans are a natural reservoir of $S$. aureus. The emergence of a pathogen community depends on its ability to survive in different environments and to interact successfully with the host. These microorganisms cause a wide range of syndromes, from skin and soft tissue minor infection up to life-threatening pneumonia and toxemy such as toxic shock syndrome. Both methicillin-sensitive and methicillin-resistant strains isolates are persistent colonizers. Rates of staphylococcal colonization

*Corresponding Author. Mailing address: Laboratory of Physical Chemistry, Department of Chemistry, San Luis National University, Lavalle 1155. 5700 San Luis, Argentina.; Tel.: 5402652426780 Int. 122 Fax: 5402652 430224.; E-mail: jmtalia@unsl.edu.ar 
are high among patients with diabetes, intravenous drug users, surgical patients and patients with the acquired immunodeficiency syndrome $(2,6)$.

Even though in the last three decades pharmacological industries have produced a number of new antibiotics, the resistance to these drugs by microorganisms has increased. In general, bacteria have the genetic ability to transmit and acquire resistance to drugs which are utilized as therapeutic agents. New infections can occur in hospitals resulting in high mortality. Such a fact is cause for concern, because of the number of patients in hospitals who have suppressed immunity, and due to new bacterial strains which are multi-resistant (13).

Methicillin-resistant Staphylococcus aureus (MRSA), identified in the early 1960s coincident with the introduction of methicillin, is now one of the most common causes of bacterial nosocomial infections, mainly in intensive care units. Methicillin resistance results from the production of an altered penicillin binding protein which has decreased affinity for most beta-lactam antibiotics $(7,24)$.

Flavonoids are phenolic substances widely distributed in all vascular plants and increasingly are becoming the subject of medical research. They have been reported to possess many properties as anti-inflammatory (4), oestrogenic (11), enzyme inhibition (9), antimicrobial (10), antiallergic (8), antioxidant (23), vascular (22) and cytotoxic antitumor (3) activities, between others. Most of the beneficial health effects of flavonoids are attributed to their ability to inhibit lipid peroxidation, chelate redox-active metals, and attenuate other processes involving reactive oxygen species (12). Related studies of antimicrobial activity indicate that crude extracts containing flavonoids, triterpenes and steroids have showed significative activity against various strains of $S$. aureus (21). The combination of antibiotics with different modes of action against bacterial cells is useful for treatment of bacterial infections. Combination effects between flavonoids and antibiotics have also been reported. Thus, Shibata et al. (20) found that flavone and its derivatives have synergistic action with the B-lactams, intensified the susceptibility in MRSA and MSSA. Furthermore, the flavonoid synergistic activity against antibiotic resistant bacteria, under low concentration minimizing the possible toxic effects, was reported $(1,18,19)$.

The aim of the present work was to investigate in vitro synergism between several chalcones substituted in combination with oxacillin, antibiotic used conventionally against S. aureus 43300 (MRSA) which is resistant to it. Kinetic turbidimetric method developed earlier was employed (15).

\section{MATERIALS AND METHODS}

\section{Compounds}

Oxacillin, sodium salt monohydrate (Sigma-Aldrich); 2',3-dihydroxychalcone (1), 2',4-dihydroxychalcone (2), 2',4'dihydroxychalcone (3) and 2',4',3-trihydroxychalcone (4) were all synthesized in our laboratory by Claisen-Schmidt condensation and identified by chromatographic and spectroscopic techniques (TLC, UV-Vis, IR, NMR) (5). In addition, 2',4'-dihydroxy-3'-methoxychalcone (5), a natural compound isolated from Zuccagnia punctata Cav., a native plant to San Luis (Argentina) (17) was assayed. Figure 1 illustrates the compound structures. Oxacillin and different chalcones solutions were prepared in absolute ethanol and diluted for antimicrobial assays.

\section{Bacterial strains}

Staphylococcus aureus ATCC 43300 (MRSA) strain (purchased from American Type Culture Collection), maintained by successive subcultures in trypticase soy agar BBL (Becton Dickinson) at $4^{\circ} \mathrm{C}$ and by lyophilization, was used.

\section{Cultura media}

Broth and agar nutritive and broth and agar Müller-Hinton (Oxoid) were used. 


\section{Kinetic-turbidimetric assays}

In order to determine quantitatively the sensitivity of $S$. aureus to oxacillin and its increase when oxacillin is used in combination with several chalcones, a previously developed kinetic-turbidimetric method was employed (15).

A $24 \mathrm{~h}$ culture of $S$. aureus ATCC 43300 in agar slant was transferred to $30 \mathrm{~mL}$ of Müller-Hinton broth and incubated at $35^{\circ} \mathrm{C}$ for $18 \mathrm{~h}$, with permanent stirring, in order to be used as inoculum. Kinetic experiments of microbial growth were performed in Erlenmeyer flasks containing $100 \mathrm{~mL}$ of MüllerHinton broth with addition of increasing concentrations of antibiotic oxacillin and $2 \mathrm{~mL}$ of previously prepared inoculum. Subsequently, Erlenmeyer flasks were incubated in a Rosi 1000 culture chamber $\left(35^{\circ} \mathrm{C}, 180 \mathrm{rpm}\right)$. Aliquots were extracted at $20 \mathrm{~min}$ intervals for $5 \mathrm{~h}$ and the transmittances were read at $720 \mathrm{~nm}$. A flask without antibiotic was used as control. This first experiment enabled us to choose the optimal oxacillin concentration to be used in the next trials $\left(6 \mu \mathrm{g} \cdot \mathrm{mL}^{-1}\right)$.

For synergism determination, similar experiments in presence of chalcone in increasing concentrations, alone or in combination with oxacillin, were performed.

In the following equation:

$$
\ln \mathrm{N}_{\mathrm{t}}=27.4-10.3 . \mathrm{T}
$$

the transmittance $(\mathrm{T})$ values at $720 \mathrm{~nm}$ were related to the number CFU/mL $\left(\mathrm{N}_{\mathrm{t}}\right)(15)$.

All trials were conducted in triplicate and standard deviations of the specific growth rate, were in all cases lower than 0.001 .

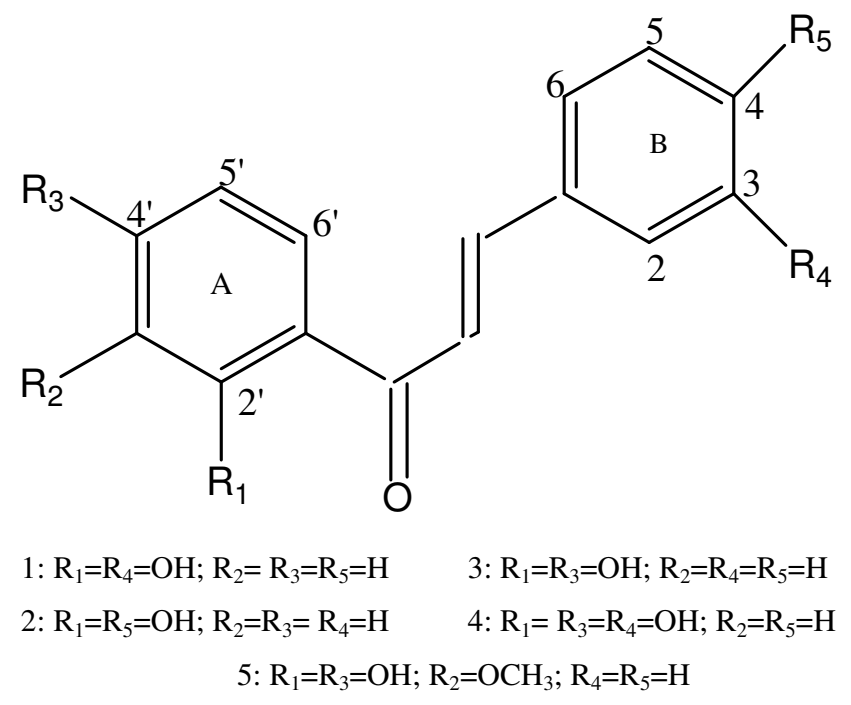

Figure 1. Structure of compounds: 1: 2',3- dihydroxychalcone; 2: 2',4- dihydroxychalcone; 3: 2',4'- dihydroxychalcone; 4: 2',4',3- trihydroxychalcone; 5: 2',4'-dihydroxy-3'-methoxychalcone.

\section{RESULTS AND DISCUSSION}

The number of CFU/mL at different times was obtained by the turbidimetric kinetic method (Eq. 1). The microbial growth can be expressed by the equation:

$$
\ln \mathrm{N}_{\mathrm{t}}=\ln \mathrm{N}_{\mathrm{o}}+\mu \cdot \mathrm{t}
$$

where $\mathrm{t}$ is time in $\min , \mathrm{N}_{\mathrm{o}}$ is $\mathrm{CFU} / \mathrm{mL}$ at $\mathrm{t}=0, \mathrm{~N}_{\mathrm{t}}$ is $\mathrm{CFU} / \mathrm{mL}$ at $\mathrm{t}=\mathrm{t}$ and $\mu$ is specific growth rate $\left(\mathrm{in} \mathrm{min}^{-1}\right)$.

Growth rates values in media with increasing chalcone 
concentration and their combinations with oxacillin constant concentration were obtained from the exponential phase of $\ln$ Nt vs. $t$ plots.
Table 1 exhibits the specific growth rates of $S$. aureus obtained in presence of chalcones isolated and chalcones oxacillin combinations with the respective MIC values.

Table 1. Specific growth rates and minimal inhibitory concentration for all systems assayed against a methicillin-resistant Staphylococcus aureus strain.

\begin{tabular}{|c|c|c|c|c|c|c|c|}
\hline \multirow[b]{2}{*}{ Chalcone } & \multicolumn{6}{|c|}{ Concentration $\left(\mu \mathrm{g} . \mathrm{mL}^{-1}\right)$} & \multirow{2}{*}{$\begin{array}{c}\text { MIC } \\
\text { Mg.mL }\end{array}$} \\
\hline & & $\mathbf{0}$ & 5.00 & 10.0 & 15.0 & 20.0 & \\
\hline \multirow[t]{2}{*}{1} & $\mu$ (isolated) & 0.0465 & 0.0380 & 0.0158 & 0.00130 & 0 & 15.8 \\
\hline & $\mu(\mathrm{comb})$ & 0.0465 & 0.0231 & 0.00616 & 0 & 0 & 11.2 \\
\hline \multirow[t]{3}{*}{2} & $\mu$ (isolated) & 0.0453 & 0.0389 & 0.0350 & 0.0314 & 0.0312 & 45.0 \\
\hline & $\mu(\mathrm{comb})$ & 0.0453 & 0.0150 & 0.0115 & 0.0112 & 0.00653 & 22.4 \\
\hline & $\mu$ (isolated) & 0.0476 & 0.0373 & 0.0247 & 0.00425 & 0.000400 & 20.1 \\
\hline 3 & $\mu(\mathrm{comb})$ & 0.0476 & 0.0296 & 0.00928 & 0.00343 & 0 & 15.3 \\
\hline \multirow[t]{2}{*}{4} & $\mu$ (isolated) & 0.0459 & 0.0386 & 0.0314 & 0.0254 & 0.0131 & 30.8 \\
\hline & $\mu(\mathrm{comb})$ & 0.0459 & 0.0279 & 0.0197 & 0.0157 & 0.00719 & 22.5 \\
\hline \multirow[t]{2}{*}{5} & $\mu$ (isolated) & 0.0464 & 0.0391 & 0.0348 & 0.0292 & 0.0244 & 42.5 \\
\hline & $\mu(\mathrm{comb})$ & 0.0464 & 0.00988 & 0.00866 & 0.00818 & 0.00766 & $\infty$ \\
\hline
\end{tabular}

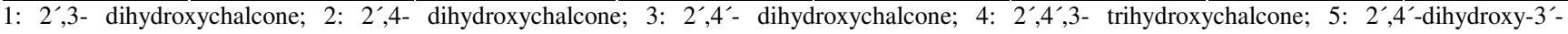
methoxychalcone. MIC: minimal inhibitory concentration.

The specific growth rate values decreasing when the experiment was made in presence of oxacillin constant concentration. This fact is observed in Table 1 for all assayed combinations. The results were satisfactory, except for $2^{\prime}, 4^{\prime}-$ dihydroxy-3'-methoxychalcone - oxacillin.

They are in accordance with bacteriostatic inhibition mechanism previously proposed (15). In the same, the exponential growth law of microorganisms and the possible adsorption of substances on the cell wall were considered, resulting in the reduction or cancellation of some vital function:

$$
\begin{gathered}
\mu_{\mathrm{T}} \\
\mathrm{N} \rightarrow 2 \mathrm{~N} \\
\mathrm{k}_{\mathrm{I}} \\
\mathrm{C}+\mathrm{N} \rightarrow \mathrm{C}-\mathrm{N}
\end{gathered}
$$

The growth rate of bacteria by this mechanism is expressed as:

$$
\mathrm{dN} / \mathrm{dt}=\mu_{\mathrm{T}} \cdot \mathrm{N}-\mathrm{k}_{\mathrm{I}} \cdot \mathrm{C} \cdot \mathrm{N} \quad \mathrm{o} \quad \mathrm{dN} / \mathrm{dt}=\left(\mu_{\mathrm{T}}-\mathrm{k}_{\mathrm{I}} \cdot \mathrm{C}\right) \mathrm{N}
$$

Comparing this relationship with the exponential growth law $\mathrm{dN} / \mathrm{dt}=\mu . \mathrm{N}$, it is inferred that:

$$
\mu=\mu_{\mathrm{T}}-\mathrm{k}_{\mathrm{I}} \cdot \mathrm{C}
$$

where $\mu_{\mathrm{T}}$ : specific growth rate without $\operatorname{drug}\left(\mathrm{min}^{-1}\right)$ (control), $\mathrm{k}_{\mathrm{I}}$ : specific inhibition rate $\left(\mathrm{mL} \cdot \mu \mathrm{g}^{-1} \cdot \mathrm{min}^{-1}\right)$ and $\mathrm{C}$ : drug concentration $\left(\mu \mathrm{g} \cdot \mathrm{mL}^{-1}\right)$. The minimal inhibhitory concentration (MIC) was calculated by extrapolation at $\mu=0$ from the graphical representation of equation 3.

For $2^{\prime}, 4^{\prime}$-dihydroxy-3'-methoxychalcone - oxacillin combination, antagonist is observed, probably due to the strong complex formation between both molecules. This fact provokes a decrease of the chalcone bacteriostatic activity. 
To facilitate comparison of the inhibitory action between structurally related substances such as chalcones and their combinations with conventional antibiotic oxacillin, should be determined the percentual bacteriostatic efficiency of a drug (PBE) (16), in the form:

$$
\mathrm{PBE}=100 / \mathrm{MIC}
$$

where MIC: minimum inhibitory concentration $\left(\mu \mathrm{g} \cdot \mathrm{mL}^{-1}\right)$ and 100: percentage arbitrary numerical factor. Evaluating chalcones PBE tested and comparing with the PBE of these chalcones with oxacillin, can be established that combinations PBE are higher, demonstrating synergism for all of them, except for $2^{\prime}, 4^{\prime}$,dihydroxy-4'-methoxychalcone - oxacillin combination (Table 2).

Table 2. Minimal inhibitory concentration and percentual bacteriostatic efficiency of isolated chalcones and of chalcones-oxacillin combinations against a methicillin-resistant Staphylococcus aureus strain.

\begin{tabular}{ccccc}
\hline Chalcone & MIC (comb) & PBE (isolated) & \multicolumn{2}{c}{ PBE (comb) } \\
\hline 1 & 11.2 & 6.33 & $<$ & 8.93 \\
2 & 22.4 & 2.22 & $<$ & 4.46 \\
3 & 15.3 & 4.97 & $<<$ & 6.53 \\
4 & 22.5 & 3.25 & $<$ & 4.44 \\
5 & 73.9 & 2.35 & $>>>$ & $\approx 0$ \\
\hline $1: 2^{\prime}, 3-2^{\prime}-2^{\prime}$
\end{tabular}

1: 2’3- dihydroxychalcone; 2: 2',4- dihydroxychalcone; 3: 2',4'- dihydroxychalcone; 4: 2',4’3- trihydroxychalcone; 5: 2',4'dihydroxy-3'-methoxychalcone. MIC: minimal inhibitory concentration.

Chalcones activity against methicillin-resistant Staphylococcus aureus (MRSA) was detected by kineticturbidimetric method. This inhibition was observed with the isolated chalcones and with their combinations with oxacillin, an ineffective antibiotic. The chalcones - oxacillin combinations showed an interesting synergic action.

Due to the growing problem of microbial resistant, the outlook for the use of antimicrobial drugs is uncertain. Consequently, the development of researches which seek to increase antibacterial activity and to characterize the interaction mechanism with antibiotics woud be desirable.

Thus, the synergistic effect between chalcones and oxacillin is an important way that could lead to the development of new combination antibiotics against MRSA infections.

\section{ACKNOWLEDGEMENTS}

This work was supported by San Luis National University, Argentina.

\section{REFERENCES}

1. Alvarez, M.A.; Debattista, N.B.; Pappano, N.B. (2008). Antimicrobial activity and synergism of some substituted flavonoids. Folia Microbiol., 53 (1), 23-28.

2. Boyle-Vavra, S.; Daum, R.S. (2007). Community-acquired methicillinresistant Staphylococcus aureus: the role of Panton-Valentine leukocidin. Lab. Investigation. 87, 3-9.

3. Cárdenas, M.; Marder, M.; Blank, V.C.; Roguin, L.P. (2006). Antitumor activity of some natural flavonoids and synthetic derivatives on various human and murine cancer cell lines. Bioorg. Med. Chem. 14, 2966-2971.

4. Cheng, W.; Li, J.; You, T.; Hu, C. (2005). Anti-inflammatory and immunomodulatory activities of the extracts from the inflorescence of Chrysanthemum indicum Linné. J. Ethnopharmacol. 101, 334-337.

5. Dhar, D.N. (1981). The Chemistry of chalcones and related compounds. John Wiley \& Sons, New York, p. 5-9.

6. Franklin, D.; Lowy, M.D. (1998). Staphylococcus aureus infections. N. Engl. J. Med. 339, 520-532

7. Hawkey, P.M.; Jones, A.M. (2009).The changing epidemiology of resistance. J. Antimicrob. Chemother. 64, i3-i10.

8. Hirose, E. ; Matsushima, M.; Takagi, K.; Ota, Y.; Ishigami, K.; Hirayama, T.; Hayashi, Y.; Nakamura, T.; Hashimoto, N.; Imaizumi, K.; Baba, K.; Hasegawa, Y.; Kawabe, T. (2009). Involvement of Heme Oxygenase-1 in Kaempferol-Induced Anti-Allergic Actions in RBL-2H3 
Cells. Inflamattion. 32, 99-108.

9. Loizzo, M. R.; Said, A.; Tundis, R.; Rashed, K.; Statti, G. A.; Hufne, A.; Menichini, F. (2006). Inhibition of angiotensin converting enzyme (ACE) by flavonoids isolated from Ailanthus excelsa (Roxb) (Simaroubaceae). Phytother. Res. 21, 32-36.

10. Mandalari, G.; Bennett, R.N.; Bisignano, G.; Trombetta, D.; Saija, A.; Faulds, C.B.; Gasson, M.J.; Narbad, A. (2007). Antimicrobial activity of flavonoids extracted from bergamot (Citrus bergamia Risso) peel, a byproduct of the essential oil industry. J. Appl. Microbiol. 103, 20562064.

11. Matsumura, A.; Ghosh, A.; Pope, G.S.; Darbre, P.D. (2005). Comparative study of oestrogenic properties of eight phytoestrogens in MCF7 human breast cancer cells. J. Steroid Biochem. Mol. Biol. 94, 383-525.

12. Mellou, F.; Lazari, D.; Skaltsa, H.; Tselepis, A.D.; Kolisis, F.N.; Stamatis, H. (2005). Biocatalytic preparation of acylated derivatives of flavonoid glycosides enhances their antioxidant and antimicrobial activity. J. Biotechnol. 116, 295-304.

13. Nascimento, G.G.F.; Locatelli, J.; Freitas, P.C.; Silva, G.L. (2000). Antibacterial Activity of Plant Extracts and Phytochemicals on Antibiotic-Resistant Bacteria. Braz. J. Microbiol. 31, 247-256.

14. O'Callaghan, R.J.; McCormick, C.C.; Caballero, A.R.; Marquart, M.E.; Gatlin, H.P.; Fratkin, J.D. (2007). Age-Related Differences in Rabbits during Experimental Staphylococcus aureus Keratitis. Invest. Ophth. Vis. Sci. 48, 5125-5131.

15. Pappano, N.B.; Centorbi, O.P.; Ferretti, F.H. (1990). Determinación de la concentración mínima inhibitoria a partir de parámetros cinéticos de crecimiento. Rev. Microbiol. 21, 183-188.

16. Pappano, N.B.; Centorbi, O.P.; Ferretti, F.H. (1994). Determination of the responsible molecular zone for the chalcones bacteriostatic activity. Rev. Microbiol. 25, 168-174.
17. Pederiva, R.; Kavka, J.; D’Arcangelo, A.T. (1985). Chalconas y flavanonas aisladas de Zuccagnia punctata Cav. An. Asoc. Quím. Argent. 63, 85-90.

18. Sato, M.; Tanaka, H.; Yamaguchi, R.; Kato, K.; Etoh, H. (2004). Synergistic effects of mupirocin and an isoflavanone isolated from Erythrina variegata on growth and recovery of methicillin-resistant Staphylococcus aureus. Int. J. Antimicrob. Ag. 24, 241-246.

19. Sato, Y.; Shibata, H.; Arai, T.; Yamamoto, A.; Okimura, Y.; Arakaki, N.; Higuti T. (2004). Variation in synergistic activity by flavone and its related compounds on the increased susceptibility of various strains of methicillin-resistant Staphylococcus aureus to $\beta$-lactam antibiotics. Int. J. Antimicrob. Ag. 24, 226-233

20. Shibata, H.; Kondo, K.; Katsuyama, R.; Kawazoe, K.; Sato, Y.; Murakami, K.; Takaishi, Y.; Arakaki, N.; Higuti, T. (2005). Alkyl Gallates, Intensifiers of B-Lactam Susceptibility in Methicillin-Resistant Staphylococcus aureus. Antimicrob. Ag. Chemother. 49, 549-555.

21. Taleb-Contini, S.H.; Salvador, M.J.; Watanabe, E.; Ito, I.Y.; Rodrigues de Oliveira, D.C. (2003).Antimicrobial activity of flavonoids and steroids isolated from two Chromolaena species. Rev. Bras. Cienc. Farm. 39, 403-408.

22. Xu, Y.C.; Leung, S.W.S.; Yeung, D.K.Y.; Hu, L.H.; Chen, G.H.; Che, C.M.; Man, R.Y.K. (2007). Structure-activity relationships of flavonoids for vascular relaxation in porcine coronary artery. Phytochemistry. 68,1179-1188

23. Yilmaz, Y.; Toledo, R.T. (2004). Major Flavonoids in Grape Seeds and Skins: Antioxidant Capacity of Catechin, Epicatechin, and Gallic Acid. J. Agric. Food Chem. 52, 255-260.

24. Zetola, N.; Francis, J. S.; Nuermberger, E. L.; Bishai, W. R. (2005). Community-acquired meticillin-resistant Staphylococcus aureus: an emerging threat. Lancet Infect. Dis. 5, 275-286. 